Authors: Krzysztof Wałęsa, Ireneusz Malujda, Krzysztof Talaśka

Title of article: „Badania empiryczne termozgrzewalnych pasów cięgnowych o przekroju kołowym” (“Experimental research of round welded drive belts")

Mechanik, Vol. 91, No. 5-6 (2018): pages 443-446

DOI: https://doi.org/10.17814/mechanik.2018.5-6.56

\title{
Experimental research of round welded drive belts
}

\author{
Badania empiryczne termozgrzewalnych pasów \\ cięgnowych o przekroju kołowym
}

\section{KRZYSZTOF WAŁESA \\ IRENEUSZ MALUJDA KRZYSZTOF TALAŚKA *}

Presented are the requirements and preliminary research assumptions for round welded elastomer belts. The strength examination problems of polyurethane belts and welds were noticed. Their results are necessary for further analysis of hot plate welding process.

KEYWORDS: drive belts, thermoplastic elastomers, butt welding

Butt welding using the hot plate method is one of the stages of the production of tension belts with a circular cross-section. They are usually made of elastomeric thermoplastics, most often polyurethane [1]. The growing demand for these elements has influenced the need to automate their production. Hence the idea of designing a device to connect them, allowing to automate manual hotplate welding. The aim of these activities is not only to improve production efficiency, but also to obtain a consistent, high quality belts.

The research concerned the butt welding by means of a hot plate of industrial tension belts with circular crosssection, made of polyurethane. One of the research stages was conducting welding tests in laboratory conditions.

In order to be able to evaluate the correctness of the connection, certain weld quality control procedures should be applied and its significant mechanical parameters, e.g. the tensile strength limit, should be measured. These results will be referred to the strength of the native material. Due to the lack of precise data on these materials, their thermomechanical properties should be investigated. The obtained material solids will also be used to develop a physical model of the butt welding process, using a hot plate, at further research stages.

In the literature, a number of works on butt welding using the hot plate method can be found. Welding tests were carried out, among others, of belts made of the same material, of various materials and reinforced with fibers or powders of other material. Typically, relatively rigid materials were tested under normal ambient conditions, e.g. polycarbonate (PC) [7,9,13], polymethylene methacrylate (PMMA) $[8,9]$, acrylonitrile-butadiene-styrene (ABS) copolymer [8], polyethylene (PE) [11] or polypropylene (PP) [10].

\footnotetext{
* Mgr inż. Krzysztof Wałęsa (krzysztof.walesa@put.poznan.pl), dr hab. inż. Ireneusz Malujda, prof. PP (ireneusz.malujda@put.poznan.pl), dr inż. Krzysztof Talaśka (krzysztof.talaska@put.poznan.pl) - Katedra Podstaw Konstrukcji Maszyn Politechniki Poznańskiej
}

When welding thermoplastic elastomers, data on material properties and parameters of the welding process are vague and insufficient for analysis.

\section{Characteristics of the welded drive belts}

The drive belts are commonly used in the drive mechanisms of industrial machines. In addition to the classic belt transmissions, with rubber and composite belts (flat, wedge and toothed), flexible tendons with a circular cross-section are popular [3]. These belts are produced from the thermoplastic elastomers, most often made of polyurethane [1]. Such materials are characterized by flexibility and the ability to obtain a large value of unstable deformation. Therefore, they can be used in drive systems where it is required to use pulleys with relatively small diameters (to provide a small radius of bending the belt). Under the influence of high temperature, these materials behave like typical thermoplastics [2]. Due to this, it is possible to connect them by butt welding using a hot plate.

The drive belts of this type have a circular section, with diameters ranging from a few to a dozen or so millimeters (fig. 1a). They are used as drive and conveyor belts in the light and food industry (fig. 1b) [15].

a)

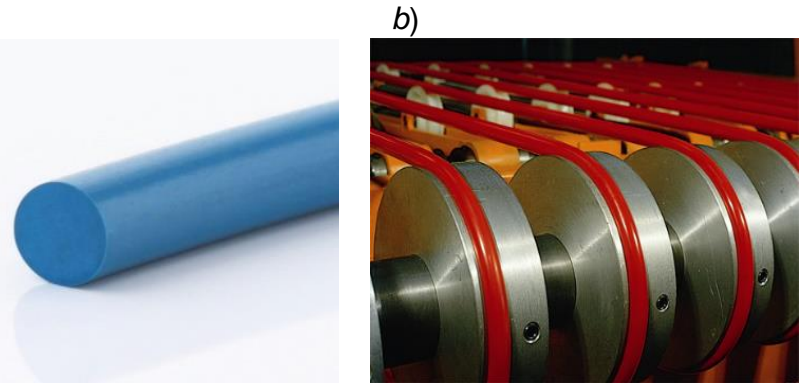

Fig. 1. Elastomeric straps with a circular cross-section [1]: a) an example of a belt with a diameter of $8 \mathrm{~mm}, b$ ) the use of belts in a conveyor of food products

\section{Requirements for thermo-weldable tension belts}

Heat-welded belts should meet a number of requirements that can be divided into two groups: normative conditions for welds and guidelines for constructors of industrial machines on the subject of finished belt. 


\section{Normative conditions for welds}

This group of requirements results from the standards set for welded joints and welded plastics. According to the PNEN 13100 standard, the joints of thermoplastics can be subjected to non-destructive testing, including:

- visual assessment,

- X-ray radiographic examinations,

- ultrasonic testing,

- high voltage tests.

For the needs of the preliminary assessment of the welds made during the welding work, a visual assessment will be sufficient. Its results will be referred to the requirements set out in the PN-EN 14728 standard or its more precise equivalent DIN DVS 2202-1, which describe typical incompatibilities of welded joints and thermoplastics.

According to these guidelines, a cooled weld will be evaluated, in which excess material in the form of flash was left. In this case, the welded joint should not have:

- cracks and notches in the area of the weld and outside it,

- spills with sharp, jagged edges whose cross-sectional area is much larger than the belt,

- thermal damage in the form of melting, reducing the cross-sectional area of connected elements or the weld itself,

- thermal damage, visible in the form of a material char as a result of exceeding the permissible temperature value beyond the limit of thermal destruction,

- unoccupied space.

Standards also specify conditionally acceptable defects of welded joints, which may include:

- small inclusions of foreign material,

- air bubbles in the weld,

- angular deviation of connected elements resulting from, for example, incorrect setting during bonding, if the angular dimension of the deviation does not exceed the permissible value,

- eccentricity or offset of welded elements,

- unevenness in the height and width of the flash on both sides of the joint.

Such defects are acceptable if they do not exceed the geometrical dimensions or quantities specified in the standard [5, 14].

Evaluation of some joint irregularities may require mechanical processing (cuts, etc.). This operation must be carried out in such a way as not to damage the joint structure, e.g. by significantly distorting the weld area.

\section{Requirements for the use of tethers}

The second group of requirements comes from the guidelines proposed by the customers of the belt belts. The belt installed in the drive mechanism should meet certain conditions resulting from the principles of machine construction, such as:

- maintaining appropriate belt dimensions in the connection area, which should be understood as the lack of diameter deviations from the average value for solid material. This is due to the requirements of drive systems. Belts usually work with precisely made rollers. Any disturbance of their geometry may introduce fluctuations in speed and torque. This in turn threatens to create undesirable vibrations and, as a consequence, additional, excessive stresses in the cross-section of the belt [4], accelerating wear. In addition, additional loads of other drive system components, e.g. bearings or shafts, which adversely affect their durability are introduced. The fulfillment of this condition requires the removal of excess material that flows out of the area of the weld,

- maintaining the concentricity of the welded ends, since its absence contributes to the inaccuracy of the belt geometry, which results in the already mentioned effects,
- accurate weld execution throughout the cross-section incomplete connection, only in the part of the transverse field of the weld, which results in lowering the belt's resistance to repeated bending, which occurs while working on pulleys,

- maintaining the proper tensile strength of the belt after welding - in the best case the tensile strength of the weld is the same as the native material. It is also important to maintain a similar stretch of the stretching curve for the weld and the solid strip. The condition is met if the elastic modulus of the weld and the belt material is the same.

Practice shows that the described abnormalities and the lack of maintaining the desired belt strength may arise due to technological errors in the connection process, e.g.:

- incorrect orientation of the belt ends in relation to each other and to the hot plate during the heating and bonding stages,

- selection of incorrect values of technological parameters of the welding process, among others: the temperature of the hot plate, the duration of individual technological stages and the pressure force during heating and bonding.

The drawback with such defects should be rejected due to the high probability of failure to meet the assumed mechanical parameters, e.g. load carrying capacity. It is connected with the possibility of its accelerated damage and disturbance of the mechanism in which the belt was used.

\section{Initial belt test procedure}

Butt belt welding tests require sequential control of the obtained results.

At the first stage of research work, welded joints made on the test bench are subject to a visual assessment in accordance with the standards.

In the second stage, after positive verification, the welds will be subjected to a tensile test on a strength machine. In the same way, the properties of a solid material without a weld will also be tested for a belt from the same production series. Obtained results will be compared with each other, which will allow to determine the empirical coefficient of relative strength of the weld [12]:

$$
f_{\mathrm{z}}=\frac{\sigma_{\mathrm{Schw}}}{\sigma_{\mathrm{GM}}}
$$

where: $\sigma_{\text {Schw }}$ - limit of tensile strength of a welded sample, $\sigma_{\mathrm{GM}}$ - limit of tensile strength of a solid material.

Its value in the ideal case should be equal to 1 . This means that the weld is as durable as the native material. It is customary in industry to consider this thesis as real, thus it is advisable to check it.

Considered will be tendons made of polyurethane with a hardness of $88^{\circ} \mathrm{Sh}$ at A Shore A scale. Two types of tension belts available in the trade offer have been selected, from which samples will be taken:

- PU 85A belt with a circular cross-section and the trade designation FBRK020GGAAA and diameter $\varnothing 2 \mathrm{~mm}$ will be designed for making cylindrical samples,

- flat belt PU 85A with a rectangular cross section and the trade designation FBK150X4GG and thickness $4 \mathrm{~mm}$ will be designed for testing flat samples with narrowing.

The producer of these belts declares the identity of the type of material from which both belts are made and the same structure of their surface.

The polyurethane test from which the belts are made is aimed at understanding its basic thermomechanical properties. It was assumed that in the first stage it will be sufficient to carry out a tensile test, thus determining:

- tensile strength of the material,

- modulus of longitudinal elasticity,

- lengthening of the belt at break. 
These tests will be repeated at room temperature of around $20^{\circ} \mathrm{C}$ and under elevated temperature conditions. Its value will be increased gradually, up to $100^{\circ} \mathrm{C}$ (this results from the maximum permissible temperature of the belt). This will allow to determine the effect of temperature increase on the possible change in the value of the basic strength parameters. The results of these tests will be the input data needed to develop the physical model of the butt welding process using the hot plate method, and comparative values for further empirical studies.

Available in the literature (e.g. in manufacturers' catalogs) information on polyurethane tethers does not contain accurate data on the strength properties of the material. Instead, you can read, for example, the permissible load per one horizontal conveyor belt. Unfortunately, it is not possible to compare these values directly with the value of the belt's tensile strength.

In the literature, you can also find material sheets of polyurethanes used in the production of tendons, made available by plastic producers. It is possible to obtain, for example, a stretching curve (fig. 2) or the dependence of the longitudinal elasticity module on the temperature (fig. 3).

However, without conducting empirical tests, it is impossible to confirm the compliance of these data with the properties of the material from which samples for welding will be taken.

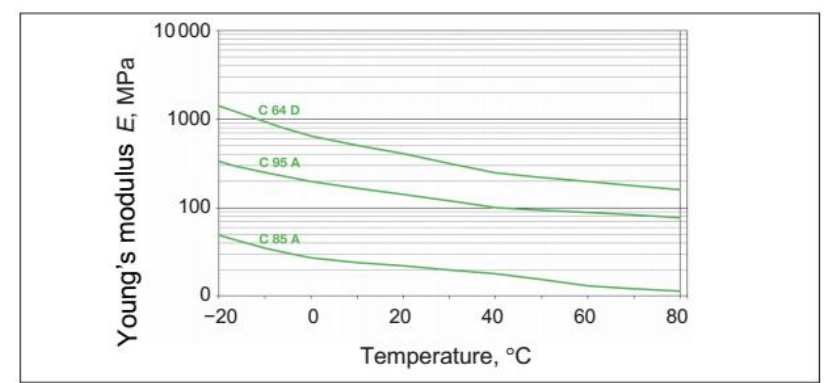

Fig. 2. Dependence of the Young's modulus on the temperature of polyurethanes, with different hardness, from the Elastollan group [6]

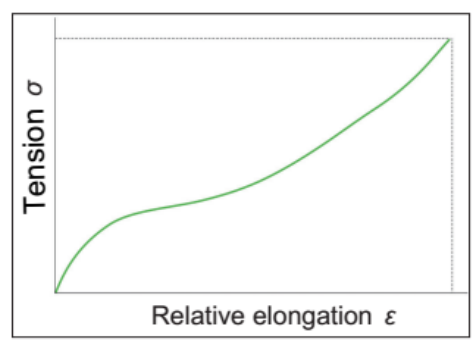

Fig. 3. Stretching curve of an exemplary polyurethane from the Elastollan group [6]

When testing material strength, it is important to adopt the appropriate geometric parameters of the samples. It was decided that at this stage:

- flat 2BA-type samples with constriction (fig. 4), made in accordance with the recommendations of PN-EN ISO 527-1 and 2 , concerning the tests of mechanical properties at static plastic stretching,

- cylindrical samples of belts with a diameter of $\varnothing 2 \mathrm{~mm}$ and a length of $75 \mathrm{~mm}$, taken from the straps produced.

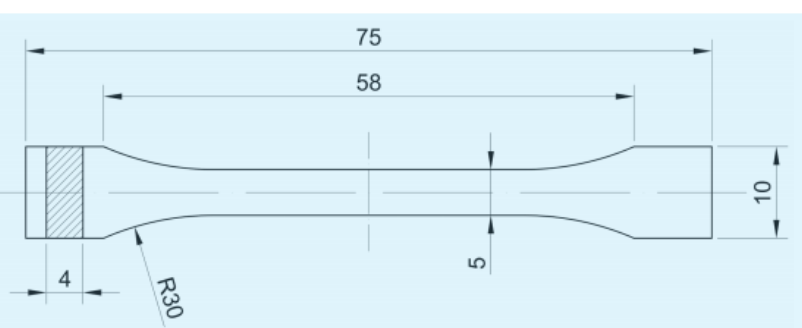

Fig. 4. Dimensions of a 1BA type flat sample for polyurethane belt tensile testing in accordance with PN-EN ISO 527-2
Tests of such cylindrical samples are not standardized. Therefore, their results will not be a reference value for further analysis of the welding process of this material. Conducting such tests is, however, deliberate, because in industrial practice belts in this form are used. It is therefore necessary to check whether such factors as:

- mechanical machining necessary to produce a two-part sample (cutting on a punch),

- differences in the technology of flat belt production (from which double-sided samples will be taken) and cylindrical (commonly used type of round belts),

- a different surface structure of both samples resulting from the mechanical treatment of the surface - they affect the strength properties of this material. Taking into account these factors, attention should also be paid to the impact of the technique of manufacturing products from which samples will be taken, e.g. for the possible orientation of macromolecules in the material, and thus for directional orientation of mechanical properties.

During the development of the methodology of strength tests of the belt material, tensile tests of a cylindrical belt sample with a diameter of $4 \mathrm{~mm}$ and a two-sided flat sample with a length of $150 \mathrm{~mm}$ were carried out (sample 1B according to PN-EN ISO 527-2). Some difficulties have been observed that have a major impact on the methodology and type of instrumentation necessary for research, including:

- too small range of displacement of the testing machine holder in the case of stretching a flat two-ended sample, which made it impossible to break the belt. During the tests, relative deformations of the belt exceeding $1000 \%$ were obtained, which with this type of sample (1B with a length of $150 \mathrm{~mm}$ and a measuring section longer than $100 \mathrm{~mm}$ ), exhausted the measuring range of the machine MTS Insight 50 , which is maximum $1050 \mathrm{~mm}$,

- picking samples in their holders or slipping them from the jaws, which made it impossible to properly grip a circular belt. When the belt clamping force in the handle was relatively small, the belts slipped. When the jaws were clamped with greater force, the samples were broken in the holder and not in the desired measuring range (i.e. between the handles). This is due to the introduction of additional stresses to the material structure while squeezing the belt ends in the holder. The cross-section of a circular belt without constrictions is characterized by approximately the same strength over the entire length, that is why the belts snapped in the holders.

Due to these problems, flat samples will be used in the research (1BA in fig. 4), conditionally admitted by the PNEN ISO 527-2 standard.

A special handle has been designed for breaking samples of cylindrical samples (fig. 6).

Strength testing of welded belt welds will be carried out according to the same methodology. This will allow to maintain the same conditions, and thus - compare the results and determine the relative coefficient of weld strength $f_{z}$.

\section{Tooling for testing the strength of belt and welds for stretching}

In the tests of stretching belts and welds using the hot plate method, the MTS Insight 50 testing machine with a climatic chamber and an extensometer adapted to work at elevated temperature will be used (fig. 5).

The climatic chamber will allow obtaining the desired elevated temperature during the tensile test. The extensometer will ensure accurate determination of the deformation of the sample, due to which it will be possible to determine the elastic modulus of the material. Standard 
wedge-shaped two-jaw handles, which are part of the MTS machine, will be used for testing flat samples.

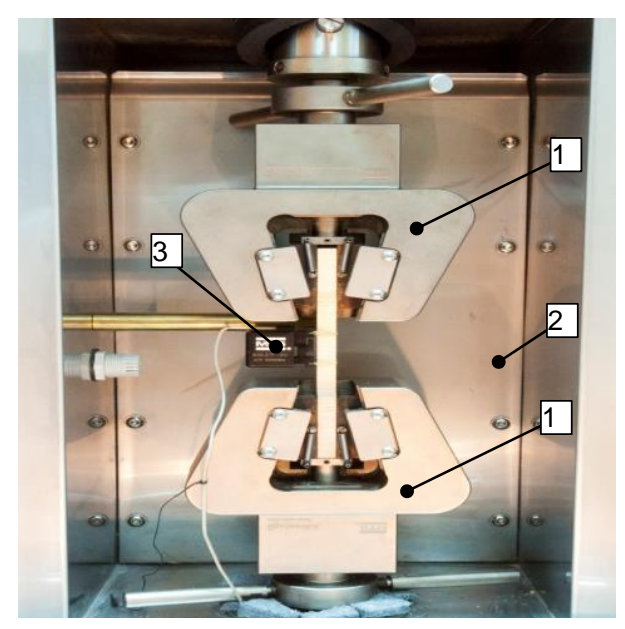

Fig. 5. MTS testing machine with a built-in climatic chamber during a tensile test: 1 - two-jaw handles, 2 - climatic chamber, 3 - extensometer

In the test of cylindrical samples a designed handle will be used (fig. 6), in which the belt is wound on a roll. This will reduce the stress in the grip section and allow the belt to break in the measuring section. Two such holders will be mounted to the testing machine using a spindle (1). It is detachably connected to the supporting plate (2) to which two vertical plates (3) are mounted by means of a positive connection. A roller (4) is mounted to the bean slots by means of a positive connection, onto which the belt will be wound. Its diameter is greater than the minimum permitted bending radius specified in the manufacturer's catalog. The end of the belt will be pressed against the flat surface by the locking plate (5).

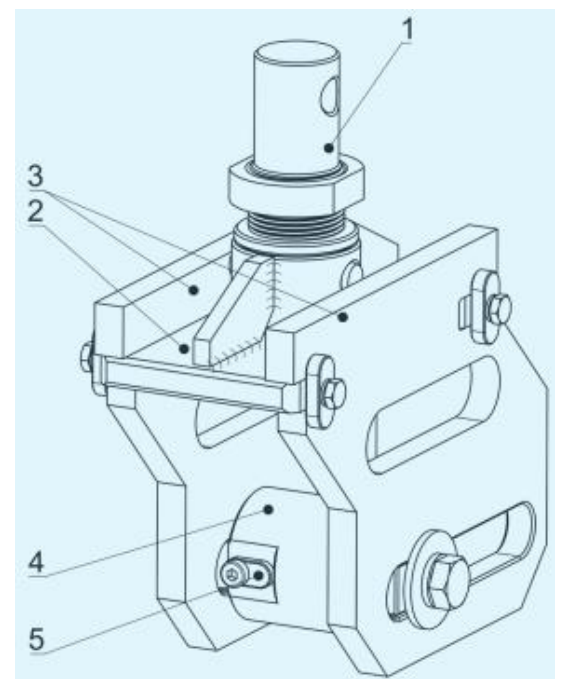

Fig. 6. Holder for testing the tensile strength of belts and welded joints: 1 - mounting bolt, 2 - bearing plate, 3 - vertical plates, 4 roll, 5 - protective plate

It is envisaged that winding the belt on the roll and immobilizing its end will enable the belt to break in the measuring range between the handles. The roll is interchangeable, which allows stretching of belts with a larger diameter, which have a larger minimum permissible bending radius. For example: for a belt with a diameter of $\varnothing 2$ $\mathrm{mm}$, made of a material with a hardness of $88^{\circ}$ according to the Shore A scale, the minimum required roller diameter is $15 \mathrm{~mm}$, while for a belt diameter $12 \mathrm{~mm}-120 \mathrm{~mm}$ [1]. In addition, the roll has the possibility of lateral displacement in the bean-shaped hole of the vertical plates and therefore it is possible to obtain an axial effect of the tensile force in relation to the sliding mechanism and measuring system of the MTS machine

\section{Conclusions}

Welded belt segments of circular cross-section, made of thermoplastic polyurethane, should meet a number of normative requirements, as well as guidelines derived from industrial practice. Initial research on welding these belts requires: testing strength properties of belt material, welds, their visual assessment and strength tests. The peculiar properties of polyurethane, e.g. high flexibility, are the source of numerous research problems, such as the difficulty in capturing cylindrical samples or the insufficient measuring range of a testing machine. During the development of the research methodology, instrumentation was designed in response to these problems. The roll holder allows you to carry out a tensile test in such a way that the material with a constant cross-section along its entire length breaks up at the desired location.

The determined values of material constants will be used for:

- assessing the quality of welds by comparing the strength of a solid material with a weld,

- developing a physical model of the welding process.

The tests will form the basis for the formulation of design assumptions for the prototype of the device for automated welding of tension belts.

\section{REFERENCES}

1. BEHAbelt. "Product Catalogue 2015/2016". Glottertal: BEHAbelt, 2015.

2. Ciszewski A., Radomski T. „Materiały konstrukcyjne $w$ budowie maszyn". Warszawa: PWN, 1989.

3. Domek G., Malujda I. „Modelling of timing belt construction”. Proceedings in Applied Mathematics and Mechanics. 7, (2007): pp. 45-46.

4. Domek G., Dudziak M. „Energy dissipation in timing belts made from composite materials". Advanced Material Research. 189-193, (2011): pp.. 4414-4418.

5. Grewell D., Benatar A. "Welding of plastics: fundamentals and new developments". International Polymer Processing. 22, 1 (2007): pp. 43-60.

6. Katalog Elastollan ${ }^{\circledR}$ - material properties, BASF.

7. Krishnan C., Benatar A. „Analysis of residual stress in hot plate welded polycarbonate". ANTEC 2004 Plastics: Annual Technical Conference. Vol. 1: Processing. (2004): s. 1149-1153.

8. Mokhtarzadeh A., Wu Ch., Benatar A. "Comparison of hot plate and vibration welding of PMMA to ABS". ANTEC 2008 Plastics: Annual Technical Conference. Proceedings. (2008): s. 856-861.

9. Mokhtarzadeh A., Wu Ch., Benatar A. "Comparison of hot plate and vibration welding of PMMA to Polycarbonate". $A N$ TEC 2008 Plastics: Annual Technical Conference. Proceedings. (2008): s. 851-855.

10. Nieh J., Lee J. „Hot plate welding of polypropylene part I: crystallization kinetics". Polymer Engineering and Science. 38 , 7 (1998): s. 1121-1132.

11. Poopat B., Benatar A. "Comparative study of contact and noncontact hot plate welding of HDPE". ANTEC 2000 Plastics: Annual Technical Conference. Vol. 1: Processing. (2000): s. 1117-1122.

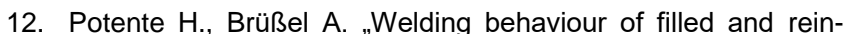
forced thermoplastics with hot plate welding". ANTEC 1998. Proceedings. (1998): s. 1062-1066.

13. Stokes V.K. „A phenomenological study of the hot-tool welding of thermoplastics. Part 1: Polycarbonate". Polymer. 40, 23 (1999): s. 6235-6263.

14. Troughton M. „Handbook of plastics joining: a practical guide”. New York: Plastics Design Library, 1997.

15. Wojtkowiak D., Talaśka K., Malujda I., Domek G. „Perforacja pasów do transportu podciśnieniowego - metody, materiały oraz problemy”. Mechanik. 17, 12 (2017): s. 1138-1142. 
Translation of scientific articles, their computer composition and publishing them on the website www.mechanik.media.pl by original articles in Polish is a task financed from the funds of the Ministry of Science and Higher Education designated for dissemination of science.

Ministry of Science and Higher Education

Republic of Poland 